\title{
다 Iℶ IMI A
}

Jurnal Gentiaras Manajemen dan Akuntasi

Laman Jurnal: jurnal.gentiaras.ac.id/index.php/Gema/index

ISSN : 2086-9592 (p) , 2721-5490 (e)

\section{Pengaruh Disiplin Terhadap Prestasi Kerja Karyawan pada PT. Semen Baturaja (Persero),Tbk. Panjang Plant}

\section{Umar Bakti ${ }^{*}$, Hairudin ${ }^{2}$}

1, 2. Universitas Mitra Indonesia, Lampung

*email:umarbakti@umitra.ac.id

\begin{tabular}{|c|c|}
\hline$A R T I C L E \quad I N F O$ & $A B S T R A C T$ \\
\hline Artikel History: & \multirow{6}{*}{$\begin{array}{l}\text { This study aims to determine the effect of discipline on employee } \\
\text { performance at PT. Semen Baturaja (Persero) for the length of the } \\
\text { plant. The sampling technique used in this study is the nonprobability } \\
\text { sampling technique. The research subjects used were PT. Semen } \\
\text { Baturaja (Persero) Tbk with a total sample of } 67 \text { employees as } \\
\text { respondents. The analytical tool used in this study is test. To get the } \\
\text { test results in this study, a classic assumption test is done, namely the } \\
\text { normality test. Then hypothesis testing is performed. Based on the } \\
\text { results of T-Test the results of the study concluded that discipline has a } \\
\text { positive influence and relationship on employee performance. }\end{array}$} \\
\hline Received:January 9, 2020 & \\
\hline Revised:August 18, 2020 & \\
\hline Published:August 19, 2020 & \\
\hline & \\
\hline $\begin{array}{l}\text { Discipline, Motivation, Competence, } \\
\text { Work performance }\end{array}$ & \\
\hline I N F O A R T I K E L & A B S T R A K \\
\hline Riwayat Artikel: & \multirow{6}{*}{$\begin{array}{l}\text { Penelitian ini bertujuan untuk mengetahui pengaruh disiplin terhadap } \\
\text { prestasi kerja karyawan pada PT. Semen Baturaja (persero) tbk panjang } \\
\text { plant. Teknik pengambilan sampel yang digunakan dalam penelitian } \\
\text { ini adalah teknik nonprobability sampling. Subjek penelitian yang } \\
\text { digunakan adalah PT. Semen Baturaja (persero) Tbk dengan jumlah } \\
\text { sampel sebanyak } 67 \text { karyawan sebagai responden. Alat analisis yang } \\
\text { digunakan dalam penelitian ini adalah uji t. Untuk mendapatkan hasil } \\
\text { pengujian dalam penelitian ini maka dilakukan uji asumsi klasik yaitu } \\
\text { uji normalitas. Selanjutnya dilakukan pengujian hipotesis. Berdasarkan } \\
\text { uji t hasil penelitian dapat disimpulkan bahwa disiplin memiliki } \\
\text { pengaruh dan hubungan yang positif terhadap prestasi kerja karyawan. }\end{array}$} \\
\hline Diterima: 9 Januari 2020 & \\
\hline Direvisi: 18 Agustus 2020 & \\
\hline Dipublikasikan: 19 Agustus 2020 & \\
\hline Kata kunci: & \\
\hline $\begin{array}{l}\text { Disiplin, Motivasi, Kompetensi, } \\
\text { Prestasi kerja }\end{array}$ & \\
\hline
\end{tabular}




\section{PENDAHULUAN}

Pertumbuhan usaha yang cukup pesat mengakibatkan berbagai persaingan perusahaan satu dengan perusahaan lainnya, situasi ini tentu memberi pengaruh terhadap kesiapan instansi perusahaan dalam rangka membuat strategi-strategi bisnis baru yang mengarah pada efisiensi dan daya saing.Persaingan dari berbagai perusahaan tersebut secara tidak langsung dapat mengakibatkan menurunnya pendapatan pada perusahaan.

Pencapaian target perusahaan tidak terlepas dari kualitas sumber daya manusia atau karyawan yang dimiliki perusahaan. Untuk itu seorang atasan perlu mempunyai ukuran prestasi kerja para karyawan.Informasi tentang prestasi kerja karyawan juga diperlukan pula bila suatu saat atasan ingin mengubah sistem yang ada. Kita sering terjebak untuk menilai seorang karyawan berprestasi kerja buruk, padahal sistem atau peralatan yang digunakanlah yang tidak memenuhi syarat.

Faktor kedisiplinan memegang peranan yang amat penting dalam pelaksanaan kerja karyawan. Seorang karyawan yang mempunyai tingkat kedisiplinan yang tinggi akan bekerja dengan baik walaupun tanpa diawasi oleh atasan. Seorang karyawan yang disiplin tidak akan mencuri waktu kerja untuk melakukan hal-hal lain yang tidak ada kaitannya dengan pekerjaan. Demikian juga karyawan yang mempunyai kedisiplinan akan mentaati peraturan yang ada dalam lingkungan kerja dengan kesadaran yang tinggi tanpa ada rasa paksaan. Pada akhirnya karyawan yang mempunyai kedisiplinan kerja yang tinggi akan mempunyai kinerja yang baik karena waktu kerja dimanfaatkannya sebaik mungkin untuk melaksanakan pekerjaan sesuai dengan target yang telah ditetapkan.

Dengan prestasi kerja karyawan yang baik maka target yang telah ditetapkan perusahaan akan tercapai. Pada PT. Semen Baturaja (Persero) Tbk kini telah merambah pasar utama di sekitar Sumatera Selatan dan Lampung serta wilayah-wilayah Indonesia yang sedang menikmati pertumbuhan ekonomi yang cukup baik dan stabil. Sasaran wilayah pemasaran ini juga sebagai langkah meningkatkan penjualan semakin meningkatnya penggunaan semen khususnya di wilayah Lampung untuk pembangunan rumah, jembatan, bendungan, gedung bertingkat dan infrastruktur lainnya. PT. Semen Baturaja mencoba mendistribusikan hingga sampai ketangan konsumen dengan baik, cepat dan tepat. Dalam pendistribusian semen PT. Semen Baturaja (Persero) Tbk. Panjang Plant terdapat data penjualan dari semester kedua atau pada bulan juli sampai dengan bulan desember 2017 penjualan semen tidak mencapai target yang di tetapkan. 


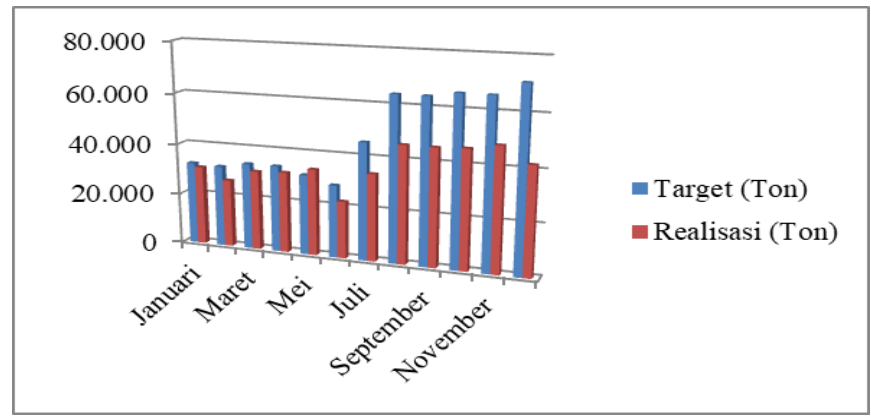

Gambar 1. Data Penjualan PT. Semen Baturaja (Persero) Tbk Panjang Plant

Sumber : PT. Semen Baturaja (Persero) Tbk. Panjang Plant Tahun 2019

Gambar 1, pada bulan Januari sampai dengan bulan Desember 2017 kenaikan atau penurunan tidak terlalu signifikan, semen yang terealisasikan tidak mencapai target, hanya pada bulan Mei penjualan melebihi target sebesar 33.713 ton dari target yang di tetapkan yaitu 31.250 ton, atau setara dengan 108\% semen yang teralisasikan kepada distributor. Pada bulan Juli sampai dengan bulan Desember mengalami penurunan yang sangat signifikan.

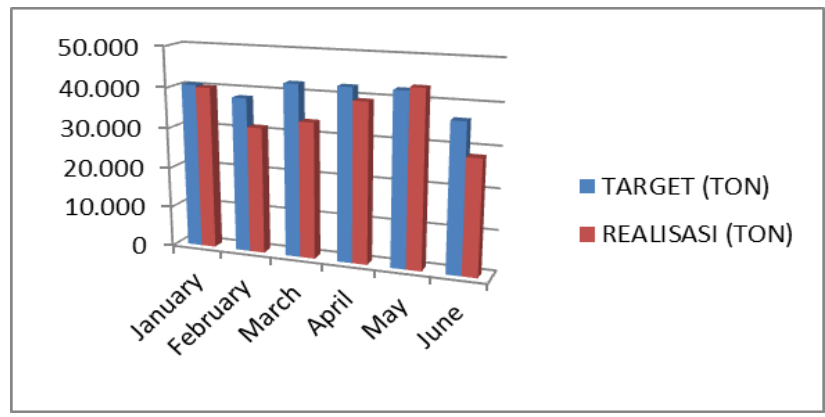

Gambar 2. Data Penjualan PT. Semen Baturaja (Persero) Tbk Panjang Plant Sumber: PT. Semen Baturaja (Persero) Tbk. Panjang Plant Tahun 2019

Gambar 2, semen yang terealisaikan tidak mencapai target, hanya pada bulan Mei penjualan melebihi target sebesar 43.274 ton dari target yang ditetapkan yaitu 42.460 ton, atau setara dengan $102 \%$ semen yang terealisasikan kepada distributor.

Pada bulan Januari sampai dengan bulan Juni 2017 kenaikan atau penurunan tidak terlalu signifikan, semen yang terealisasikan tidak mencapai target, hanya pada bulan Mei penjualan melebihi target sebesar 33.713 ton dari target yang di tetapkan yaitu 31.250 ton, atau setara dengan $108 \%$ semen yang teralisasikan kepada distributor. Pada bulan Juli sampai dengan bulan Desember mengalami penurunan yang sangat signifikan, pada tabel tahun 2018 semen yang terealisaikan tidak mencapai target, hanya pada bulan Mei penjualan melebihi target sebesar 43.274 ton dari target yang ditetapkan yaitu 42.460 ton, atau setara dengan 102\% semen yang terealisasikan kepada distributor. 
Berdasarkan uraian latar belakang diatas maka peneliti tertarik melakukan penelitian dengan mengambil judul "Pengaruh Disiplin Terhadap Prestasi Kerja Karyawan Pada PT. Semen Baturaja (Persero) Tbk. Panjang Plant". Berdasarkan uraian diatas, maka dapat dirumuskan permasalah dalam penelitian ini yaitu untuk melihat pengaruh disiplin terhadap prestasi kerja karyawan pada PT. Semen Baturaja (Persero) Tbk. Panjang Plant.

\section{Kajian Teori \\ Kedisiplinan}

Menurut Hasibuan (2010a) kedisiplinan adalah kesadaran dan kesediaan seseorang mentaati semua peraturan perusahaan dan norma-norma sosial yang berlaku. Disiplin yang baik mencerminkan besarnya tanggung jawab seseorang terhadap tugas-tugas yang diberikan kepadanya. Hal ini akan mendorong gairah kerja, semangat kerja, dan terwujudnya tujuan organisasi.

Menurut Malayu Hasibuan (2010a), indikator yang mempengaruhi tingkat kedisiplinan karyawan suatu organisasi, diantaranya: Tujuan dan Kemampuan, Teladan Kepemimpinan, Balas Jasa, Pengawasan Melekat, Sanksi Hukuman.

\section{Prestasi Kerja}

Menurut Bernadin dan Russel dalam Edy Sutrisno memberikan definisi tentang prestasi kerja adalah catatan hasil-hasil yang diperoleh dari fungsi-fungsi pekerjaan tertentu atau kegiatan tertentu (Sutrisno, 2010).

Menurut Byars dan Rue dalam Edy Sutrisno mengartikan prestasi sebagai tingkat kecakapan seseorang pada tugas-tugas yang mencakup pada pekerjaannya.Pengertian tersebut menunjukan pada bobot kemampuan individu di dalam memenuhi ketentuan-ketentuan yang ada di dalam pekerjaannya (Sutrisno, 2010). Berdasarkan pendapat sebelumnya, maka dapat disimpulkan bahwa prestasi kerja adalah sebagai hasil kerja yang telah dicapai seseorang dari tingkah laku kerjanya dalam melaksanakan aktivitas kerja.

Menurut Edy Sutrisno pengukuran prestasi kerja diarahkan pada pada enam aspek yang merupakan bidang prestasi kunci bagi perusahaan yang bersangkutan. Bidang prestasi kunci tersebut adalah Hasil kerja, Pengetahuan pekerjaan, Inisiatif, Kecekatan mental, Sikap, Disiplin waktu dalam absensi (Sutrisno, 2010). 


\section{METODOLOGI PENELITIAN}

Desain penelitian deskriptif adalah desain penelitian yang disusun dalam rangka memberikan gambaran dalam rangka memberikan gambaran secara sistematis tentang informasi ilmiah yang berasal dari subjek atau objek penelitian. Penelitian deskriptif berfokus pada penjelasan sistematis tentang fakta yang diperoleh saat penelitian dilakukan (Sanusi, 2016)

\section{Populasi dan Sampel}

Menurut Sugiyono, Populasi adalah wilayah generalisasi yang terdiri atas objek subjek yang mempunyai kualitas dan karakteristik tertentu yang ditetapkan oleh peneliti untuk dipelajari dan kemudian ditarik kesimpulannya (Sugiyono, 2015). Dalam penelitian ini yang menjadi populasi adalah seluruh karyawan PT. Semen Baturaja (Persero) Tbk. Panjang Plant.Jumlah populasi dalam penelitian ini adalah 67 karyawan

Menurut Sugiyono menyatakan bahwa sampel merupakan bagian jumlah dan karakteristik yang dimiliki oleh populasi tersebut (Sugiyono, 2015). Dalam penelitian ini teknik sampling yang digunakan nonprobability sampling adalah teknik pengambilan sampel yang tidak memberi peluang/kesempatan sama bagi setiap unsur atau anggota populasi untuk dipilih menjadi sampel. Teknik sampel ini sampling jenuh teknik adalah teknik penentuan sampel bila semua populasi digunakan sebagai sampel (Sugiyono, 2012). Jadi dalam penelitian ini penulis mengambil sampel sebanyak 67 karyawan (responden).

\section{Teknik Pengumpulan Data}

Teknik yang dipakai dalam mengumpulkan data penulisan ini adalah sebagai berikut.

a) Kuesioner

Teknik kuesioner dengan memberikan dan menyebarkan daftar penyataan kepada para responden yang terkait dalam penelitian ini, dengan harapan agar mereka memberi respon atas daftar pertanyaan tersebut. Kemudian jawaban dari setiap responden diberi skor dengan skala Likert yang mempunyai gradasi dari sangat positif sampai sangat negative dengan jumlah 5 point yaitu Sangat Tidak Setuju (STS) dengan nilai 1, Tidak Setuju (TS) dengan nilai 2, Ragu-Ragu (RG) dengan nilai (3), Setuju (S) dengan nilai 4, serta Sangat Setuju (SS) dengan nilai 5. 
b) Studi Pustaka

Merupakan sarana pembantu peneliti dalam mengumpulkan dataatau informasi dengan cara membaca surat-surat, jurnal-jurnal, pernyataan tertulis kebijakan tertentu dan bahanbahan tulisan lainnnya yang berkaitan dengan obyek penelitian (Siregar, 2015)

\section{Definisi Operasional Variabel}

Berikut operasionalisasi variabel untuk disiplin kerja, motivasi, kompetensi dan prestasi kerja dalam bentuk tabel agar lebih mudah untuk dipahami.

Tabel 1. Operasionalisasi Variabel

\begin{tabular}{|c|c|c|c|}
\hline Variabel & Konsep Variabel & Indikator & Skala \\
\hline $\begin{array}{c}\text { Disiplin } \\
\text { (X1) }\end{array}$ & $\begin{array}{l}\text { Menurut Hasibuan, Kesadaran dan } \\
\text { kesediaan seseorang mentaati semua } \\
\text { peraturan perusahaandan norma- } \\
\text { norma sosial yang berlaku } \\
\text { (Hasibuan, 2012). }\end{array}$ & $\begin{array}{l}\text { 1. Tujuan dan Kemampuan } \\
\text { 2. Teladan pimpinan } \\
\text { 3. Keadilan } \\
\text { 4. Sanksi hukuman } \\
\text { 5. Hubungan kemanusiaan }\end{array}$ & $\begin{array}{l}\text { Skala } \\
\text { Likert }\end{array}$ \\
\hline $\begin{array}{c}\text { Prestasi } \\
\text { Kerja (Y) }\end{array}$ & $\begin{array}{l}\text { Menurut Byars dan Rue dalam Edy } \\
\text { Sutrisno mengartikan prestasi } \\
\text { sebagai tingkat kecakapan seseorang } \\
\text { pada tugas -tugas yang mencakup } \\
\text { pada pekerjaannya (Sutrisno, 2010). }\end{array}$ & $\begin{array}{l}\text { 1. Hasil kerja } \\
\text { 2. Pengetahuan pekerjaan } \\
\text { 3. Inisiatif } \\
\text { 4. Kecekatan mental } \\
\text { 5. Sikap } \\
\text { 6. Disiplin waktu dalam absensi }\end{array}$ & $\begin{array}{l}\text { Skala } \\
\text { Likert }\end{array}$ \\
\hline
\end{tabular}

Sumber Data Primer Diolah Tahun 2018

\section{Teknik Analisis Data}

\section{Uji Asumsi Klasik}

Uji asumsi klasik merupakan uji prasyarat jika menggunakan analisis regresi linier. Uji asumsi klasik ini meliputi: uji normalitas residual

\section{Uji Normalitas Data}

Uji normalitas bertujuan untuk menguji apakah dalam sebuah model regresi, variabel dependen memiliki distribusi normal atau tidak dengan membandingkan distribusi komulatif dari data sesungguhnya dengan distribusi komulatif dari distribusi normal. Data normal memiliki bentuk seperti lonceng. Alat analisis yang digunakan dalam penelitian ini adalah uji P-Plot dan histogram. 


\section{Uji Hipotesis (Uji T)}

Uji $\mathrm{T}$ merupakan pengujian terhadap koefisien regresi secara farsial yaitu untuk mengetahui signifikansi peran secara farsial antara variabel independen terhadap dependen dengan asumsi tingkst signifikansi 5\%.Nilai T hitung dari masing-masing koefesien regresi dibanding $\mathrm{T}$ tabel. Jika $\mathrm{T}$ hitung > $\mathrm{T}$ tabel maka masing-masing variabel independen berpengaruh signifikan terhadap variabel dependen dan jika $\mathrm{T}$ hitung $<\mathrm{T}$ tabel maka masingmasing variabel independen tidak berpengaruh terhadap variabel dependen dengan $\alpha=5 \%$ maka untuk menentukan apakah pengaruhnya signifikan atau tidak dilakukan analisis peluang galat $(\mathrm{p})$.

\section{PEMBAHASAN}

\section{Hasil Analisis Data}

\section{a) Uji Asumsi Klasik}

\section{1) Hasil Uji Normalitas}

Pengujian normalitas dalam penelitian ini yaitu melalui normal probability plot dan historam dengan menggunakan SPSS 23 dan diperoleh hasil sebagai berikut:

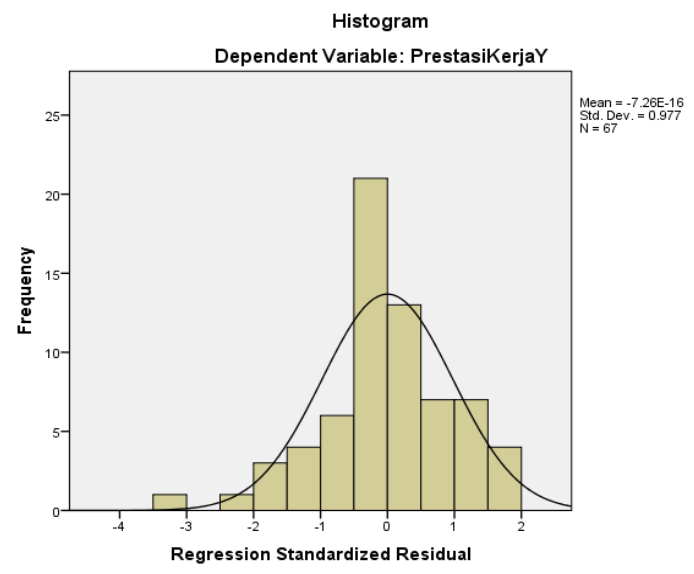

Gambar 3. Hasil Uji Normalitas Residual Sumber: Data Primer, 2019 (Data diolah)

Berdasarkan uji normal Probability plot yang dilakukan sudah memenuhi syarat karena penyebaran data disekitar garis diagonal akan tetapi ada satu data yang outlier (pencilan). Berikut hasil pengujian P Plot residual: 


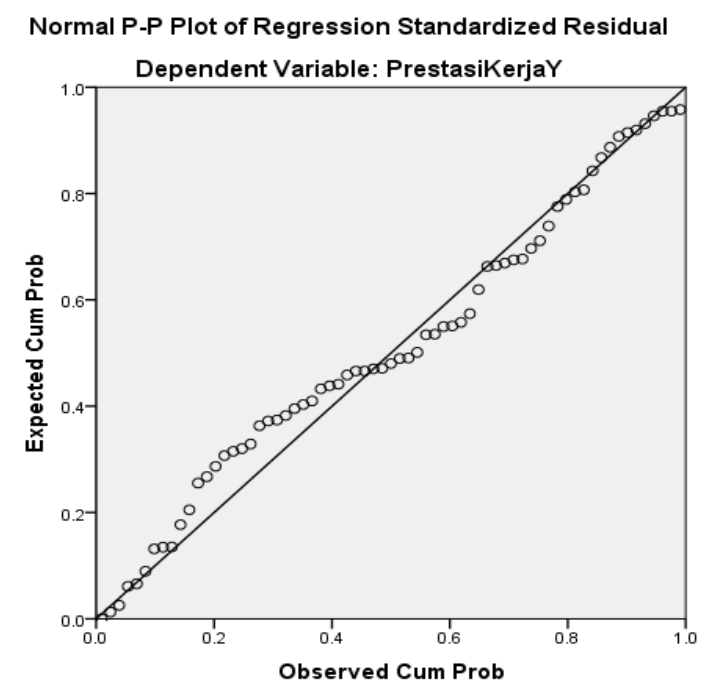

Gambar 4. Hasil Uji Normalitas Residual Sumber: Data Primer, 2019 (Data diolah)

Pada grafik normal P-plot residual terlihat titik-titik mengikuti dan mendekati garis diagonalnya.

\section{Hasil Uji Hipotesis(Hasil Uji Statistik T)}

Tabel 2. Hasil Uji T

\section{Coefficients $^{\mathrm{a}}$}

\begin{tabular}{|c|c|c|c|c|c|}
\hline \multirow[t]{2}{*}{ Model } & \multicolumn{3}{|c|}{ Unstandardized CoefficientsStandardized Coefficients } & \multirow[b]{2}{*}{$\mathrm{t}$} & \multirow[b]{2}{*}{ Sig. } \\
\hline & B & Std. Error & Beta & & \\
\hline 1(Constant) & 3.849 & 1.742 & & 2.2 & 0.031 \\
\hline DisiplinX1 & .290 & .090 & .298 & 3.2 & 0.002 \\
\hline
\end{tabular}

a. Dependent Variable: PrestasiKerjaY

Sumber: Data Primer 2019 (Data diolah)

Tabel 2, hasil uji T secara parsial dapat disimpulan dalam penelitian ini adalah Variabel independen disiplin (X1) dengan thitung 3,240>1,99834sedangkan nilai signifikan dari hipotesis sebesar 0,002<0,05. Maka Ho diterima dan Ha diterima, dapat disimpulkan bahwa variabel disiplin (X1) tidak berpengaruh tidak signifikan terhadap prestasi kerja. 


\section{Pembahasan}

Kajian ini bertujuan untuk mengetahui sejauh mana pengaruh disiplin dan motivasi terhadap prestasi kerjapada PT Semen Baturaja yang diukur dengan indikator disiplin dan motivasi. Berdasarkan hasil pengujian regresi dapat diuraikan pembahasan dari hasil analisis regresi yaitu berdasarkan hasil uji $t_{\text {hitung }}$ untuk variabel disiplin kerja sebesar 3,240 ( $\left.t_{\text {hitung }} 3,240>t_{\text {tabel }} 1,99834\right)$ dan sig 0,002 < 0,05 yang berarti disiplin berpengaruh secara signifikan terhadap prestasi kerja karyawan pada PT. Semen Baturaja (Persero) Tbk Panjang Plant.

Hal ini didukung oleh teori yang dikemukakan oleh Wahjono (2015) bahwa Disiplin merupakan perasaan taat dan patuh terhadap nilai-nilai yang dipercaya termasuk melakukan pekerjaan tertentu yang menjadi tanggung jawabnya.

Disiplin merupakan alat yang digunakan para manajer untuk berkomunikasi dengan karyawan agar mereka bersedia untuk mengubah suatu perilaku serta sebagai suatu upaya untuk meningkatkan kesadaran dan kesediaan seseorang mentaati semua peraturan perusahaan dan norma-norma sosial yang berlaku. Penelitian ini sejalan dengan penelitian yang dilakukan oleh Soelehan dkk (2009), (Tua dkk (2014), (Rofi, 2012), Rahmawati dkk (2013), Parhusip dkk (2014), Lagale dkk (2014) dan (Sukimin, P. Dhiana, \& H. Budi, 2016) yang menyatakan bahwa disiplin berpengaruh secara signifikan terhadap prestasi kerja karyawan.

\section{KESIMPULAN}

Berdasarkan hasil analisis linier berganda secara parsial (Uji T) maka dapat disimpulkan bahwa disiplin telah diterapkan pada PT. Semen Baturaja (Persero) Tbk Panjang Plant memiliki pengaruh dan hubungan yang positif terhadap prestasi kerja karyawan.

\section{DAFTAR PUSTAKA}

Hasibuan, M. S. . (2010a). Organisasi dan Motivasi. Jakarta: Bumi Aksara.

Lagale, D. G., Mekel, P. A., \& Sepang, J. L. (2014). Pelatihan, Disiplin Kerja dan Kualitas Kerja Terhadap Prestasi Kerja pada PT. PLN ( PERSERO ) Area Manado. Jurnal Emba, 2(2), 935943.

Parhusip, C. M. D., Musadieq, M. Al, \& Nurtjahjono, E. G. (2014). ( Studi Pada Karyawan AJB Bumiputera 1912 Cabang Kayutangan Kota Malang. Jurnal Administrasi Bisnis (JAB), 9 (1), 
$1-10$.

Rahmawati, A. H., Hamid, D., \& Utami, H. N. (2013). Pengaruh Disiplin Kerja Dan Pengalaman Kerja Terhadap Prestasi Kerja Karyawan. Jurnal Administrasi Bisnis (JAB), 6 (2), 1-9.

Rofi, A. N. (2012). Pengaruh Disiplin Kerja Dan Pengalaman Kerja Terhadap Prestasi Kerja Karyawan Pada Departemen Produksi PT. Leo Agung Raya Semarang. Jurnal Ilmu Manajemen Dan Akuntansi Terapan, 3 (1), 1-21.

Sanusi, A. (2016). Metodologi Penelitian Bisnis. Jakarta: Salemba Empat.

Soelehan, A., \& Sukartaatmadja, I. (2009). Semangat Kerja Terhadap Prestasi Kerja Warga Smp Perintis , Kecamatan Pancoran Mas Kota Depok. Jurnal Ilmiah Ranggagading, 9 (1), 61-69.

Sugiyono. (2012). Metode Penelitian Kuantitatif, Kualitatif, Dan $R \&$ D. Bandung: Alfabeta.

Sugiyono. (2015). Metode Penelitian Kuantitatif, Kualitatif, Dan $R \&$ D. Bandung: Alfabeta.

Sukimin, P. Dhiana, P., \& H. Budi, L. (2016). Pengaruh Pengawasan, Motivasi Dan Disiplin Kerja Terhadap Prestasi Kerja. Journal of Management, VII (2), 75-86.

Sutrisno, E. (2010). Manajemen Sumber Daya Manusia. Jakarta: Predana Media Group.

Tua, A., Tewal, B., \& Karuntu, M. (2014). Konsep Diri, Pendidikan Dan Pelatihan, Disiplin Kerja Terhadap Prestasi Kerja Pegawai Di Kejaksaan Tinggi Sulawesi Utara. Jurnal Riset Ekonomi, Manajemen, Bisnis Dan Akuntansi, 2 (1).

Wahjono, S. I. (2015). Manajemen Sumber Daya Manusia. Jakarta: Salemba Empat. 